\title{
Ghrelin administration affects circulating pituitary and gastro-entero-pancreatic hormones in acromegaly
}

\author{
M Arosio ${ }^{1,4}$, C L Ronchi ${ }^{1}$, C Gebbia ${ }^{2}$, S Pizzinelli ${ }^{2}$, D Conte ${ }^{2}$, V Cappiello ${ }^{1}$, P Epaminonda $^{1,4}$, B M Cesana ${ }^{3}$, \\ $\mathrm{P}$ Beck-Peccoz ${ }^{1}$ and $\mathrm{M}$ Peracchi ${ }^{2}$ \\ ${ }^{1}$ Institute of Endocrine Sciences, ${ }^{2}$ Department of Medical Sciences and ${ }^{3}$ Epidemiology Unit, University of Milan, Ospedale Maggiore IRCCS, \\ via F Sforza, 35, Milan, Italy and ${ }^{4}$ Operative Unit of Endocrinology, Ospedale S Giuseppe-Fatebenefratelli, AFaR, via S Vittore, 12, 20100 Milan, Italy \\ (Correspondence should be addressed to M Arosio, UO Endocrinologia, Ospedale S Giuseppe, Via S Vittore, 12, 20123 Milan, Italy; \\ Email: maura.arosio@unimi.it)
}

\begin{abstract}
Objective: Ghrelin, a gut-brain peptide involved in the control of energy homeostasis, affects anteropituitary and gastro-entero-pancreatic (GEP) hormone secretion in healthy subjects. We aimed to verify whether such hormonal responses are retained in acromegaly, a disease characterized by high GH, subnormal ghrelin and abnormal GEP hormone levels.

Design and methods: The effect of ghrelin $(3.3 \mu \mathrm{g} / \mathrm{kg}$ given after overnight fasting as an i.v. bolus) on $\mathrm{GH}$, prolactin (PRL), adrenocorticotropin (ACTH), cortisol, insulin, glucose, total somatostatin (SS) and pancreatic polypeptide (PP) circulating levels were evaluated in seven non-diabetic patients with newly diagnosed acromegaly and in nine healthy controls.

Results: Ghrelin elicited a prompt, marked increase of serum GH and PRL levels in all normal (from $1.6 \pm 0.6$ to $52.9 \pm 7.8$ and from $9.7 \pm 0.8$ to $24.2 \pm 4.8 \mu \mathrm{g} / \mathrm{l}$ (means \pm S.E.M.), respectively) and acromegalic subjects (from $11.2 \pm 4.9$ to $91.6 \pm 21.0$ and from $42.9 \pm 26.1$ to $113.8 \pm 79.0 \mu \mathrm{g} / \mathrm{l}$, respectively). Both plasma ACTH and serum cortisol levels rose significantly in the controls, whereas the cortisol response was blunted in the acromegalic patients. Glucose levels rose earlier and insulin levels fell later in all subjects, with a significantly greater net insulin decrease in acromegalic than in healthy subjects $(-80 \pm 21$ vs $-17 \pm 4 \mathrm{pmol} / \mathrm{l}, \mathrm{P}<0.01)$. A prompt PP rise and a biphasic SS response occurred in all controls, whereas in the acromegalic group the PP response (from 26.1 \pm 5.0 to $92.2 \pm 39.0 \mathrm{pmol} / \mathrm{l}$ ) and the SS response (from $11.9 \pm 3.0$ to $19.7 \pm 4.0 \mathrm{ng} / \mathrm{l}$ ) were quite variable. Conclusions: Ghrelin affects both pituitary and GEP hormones in acromegalic patients as in normal subjects. These findings suggest that ghrelin actions on the energy balance are mediated by complex interactive endocrine loops that involve also the gut and pancreas.
\end{abstract}

European Journal of Endocrinology 150 27-32

\section{Introduction}

Ghrelin, the recently discovered gut-brain hormone with well-known powerful growth hormone (GH)releasing activity $(1,2)$, regulates energy homeostasis by increasing food intake and fat deposition $(3,4)$ and modulates the endocrine system by stimulating prolactin (PRL) and adrenocorticotropic hormone (ACTH) secretion in healthy human subjects (5). Its PRL-releasing activity seems to be due to a direct effect on mammosomatotroph cells (6), whereas the release of ACTH appears to be mediated by ghrelin at the hypothalamic level (6). Moreover, in the rat, ghrelin modulates gastric motility and acid secretion $(7,8)$, inhibits gastric emptying (7) and increases insulin and gastrin secretion (9). In healthy humans, ghrelin reduces insulin secretion $(10,11)$ and increases both somatostatin (SS) and pancreatic polypeptide (PP) circulating levels but does not influence plasma gastrin levels (11). All these findings suggest important links between ghrelin and other gastro-entero-pancreatic (GEP) hormones.

In acromegaly, a disease characterized by persistently elevated GH concentrations, alterations in circulating levels of some GEP hormones $(12,13)$ and subnormal concentrations of ghrelin have been described (14, 15). It is still not known if this pathological condition modifies the pituitary and/or GEP hormone responses to pharmacological ghrelin administration. Therefore, we evaluated the effects of ghrelin administration on GH, PRL, ACTH, cortisol, insulin, glucose, SS and PP levels in patients with active acromegaly. 


\section{Patients and methods}

\section{Subjects}

Seven consecutive patients with newly diagnosed acromegaly (one man and six women, aged 32-69 years,

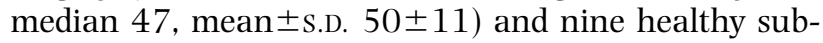
jects (four men and five women, aged 24-52 years, median 27, mean \pm S.D. $30 \pm 6$ ) recruited among medical staff volunteered for this study, which was approved by the local ethics committee. The healthy subjects had normal physical examinations and no history of gastrointestinal, endocrine or eating disorders, and were not taking any medication. The acromegalic patients had the characteristic clinical features of the disease, elevated age-adjusted serum insulin-like growth factor I (IGF-I) concentrations (ranging from 52 to $117 \mathrm{nmol} / \mathrm{l}$, median 78.4, mean \pm S.D. 77.0 22.0 ), and elevated serum GH levels (ranging from 2.3 to $35.8 \mu \mathrm{g} / \mathrm{l}$, median 5.0, mean \pm S.D. 11.2 \pm 13.0 ), not suppressible to less than $1 \mu \mathrm{g} / \mathrm{l}$ during a $75 \mathrm{~g}$ oral glucose tolerance test. At pituitary imaging, two patients had a pituitary microadenoma and five a macroadenoma, intrasellar in three and with extrasellar extension in two. Two patients had elevated basal PRL levels (32 and $198 \mu \mathrm{g} / \mathrm{l}$ respectively). None had associated pituitary hormone deficiencies as assessed by specific central and peripheral hormone assays. Two patients showed impaired glucose tolerance, but no patient had diabetes mellitus. None of the patients had been treated previously for acromegaly. Five patients were subsequently operated on, which revealed a mixed GH-PRL adenoma in the two with hyperprolactinaemia and a pure $\mathrm{GH}$ adenoma in the other three.

\section{Procedures}

After an overnight fast an i.v. catheter was inserted in a forearm vein between 0800 and $0900 \mathrm{~h}$ and kept patent by slow saline infusion. After $1 \mathrm{~h}$ of bed rest, all the subjects received an i.v. bolus injection of human ghrelin (Europeptides, Argenteuil, France) at a dose of $3.3 \mu \mathrm{g} / \mathrm{kg}$. This pharmacological dose was chosen because it has previously been shown to be effective in eliciting GH release in humans (2), and in our hands it induced serum ghrelin peaks ranging from 2.0 to $4.9 \mathrm{nmol} / \mathrm{l}$ (11). Blood samples were taken at $-30,0,15,30,45,60,90,120,150$ and $180 \mathrm{~min}$. Plasma samples for SS and PP assays were collected in ice-chilled polypropylene tubes containing EDTA $(1 \mathrm{mg} / \mathrm{ml})$ and aprotinin $(500 \mathrm{kIU} / \mathrm{ml})$, separated immediately by centrifugation at $4{ }^{\circ} \mathrm{C}$, and stored at $-80^{\circ} \mathrm{C}$ until assayed. Samples for ACTH assay was collected in ice-chilled tubes containing EDTA, separated immediately at $4{ }^{\circ} \mathrm{C}$ and stored at $-20^{\circ} \mathrm{C}$. Serum for GH, IGF-I, PRL, cortisol, insulin and glucose determinations was separated at room temperature and stored at $-20^{\circ} \mathrm{C}$.

\section{Methods}

Serum GH, PRL and cortisol levels were measured by IFMA (AutoDelfia kit; Wallac, Inc. OY, Turku, Finland), plasma ACTH by chemoluminescence immunometric assay (Nichols Institute Diagnostics, San Juan Capistrano, CA, USA), serum insulin by ELISA (MedgenixIns-EASIA; Biosource Technologies, Inc. Europe, Nivelles, Belgium), serum IGF-I by RIA (Mediagnost, Tübingen, Germany) and plasma glucose concentrations by a glucose autoanalyser with the hexokinase method (Beckman, Milan, Italy). Plasma SS and PP levels were measured after extraction on Sep-Pak C 18 cartridges by RIA kits (Peninsula Laboratories, Inc., Belmont, CA, USA) as previously described (11). The intra- and interassay coefficients of variation were less than $10 \%$ for all methods.

\section{Statistical analysis}

The integrated areas of secretion (AUC) were calculated with the trapezoidal method, incremental areas $(\Delta$ AUC) were calculated when appropriate by subtracting basal values. Statistical analyses of the peak/nadir and area data (response rate and mass secretion phenomenon) were performed by non-parametric tests (Mann-Whitney or Wilcoxon, as appropriate). The pattern of the recorded values over the time has been assessed, after natural logarithmic transformation, by means of an ANOVA for repeated measurements model; in the case of a statistical significance of the interaction group by time term, multiple comparisons have been carried out on the simple effect (difference between the two groups keeping the time levels fixed) adjusting the significance level by simulation with SAS (Release 8.2) Proc Mixed. Relationships between hormones have been analysed by Bravais-Pearson's correlation coefficient. Results are expressed as means \pm s.e.M. A $P$ value $<0.05$ was considered statistically significant.

\section{Results}

The results are summarized in Table 1 and Figs 1 and 2. No age- or sex-related differences were observed in any of the variables considered in either group of subjects.

\section{Fasting conditions}

Basal serum GH and insulin and plasma glucose concentrations were significantly higher in the acromegalic patients than in the healthy subjects whereas the levels of the other hormones assayed were similar in both groups (Table 1). 
Table 1 Hormonal and metabolic responses to administration of ghrelin bolus $3.3 \mu \mathrm{g} / \mathrm{kg}$ in nine healthy controls and seven acromegalic patients. Data are given as means \pm S.E.M.

\begin{tabular}{|c|c|c|c|c|c|c|}
\hline & \multicolumn{3}{|c|}{ Controls } & \multicolumn{3}{|c|}{ Acromegalic patients } \\
\hline & Baseline $^{a}$ & Peak/nadir ${ }^{b}$ & AUC (180 min) & Baseline $^{a}$ & Peak/nadir ${ }^{b}$ & AUC (180 min) \\
\hline $\mathrm{GH}(\mu \mathrm{g} / \mathrm{l})$ & $1.6 \pm 0.6$ & $52.9 \pm 7.8^{d}$ & $3049 \pm 645$ & $11.2 \pm 4.9^{f}$ & $91.6 \pm 21.0^{\mathrm{e}}$ & $6427 \pm 2012$ \\
\hline $\operatorname{PRL}(\mu \mathrm{g} / \mathrm{l})$ & $9.7 \pm 0.8$ & $24.2 \pm 4.8^{\mathrm{d}}$ & $4677 \pm 1258$ & $42.9 \pm 26.1$ & $114 \pm 79^{e}$ & $11826 \pm 7228$ \\
\hline ACTH $(\mathrm{pmol} / \mathrm{l})$ & $4.0 \pm 0.7$ & $11.4 \pm 1.9^{d}$ & $694 \pm 87^{c}$ & $5.0 \pm 0.5$ & $14.8 \pm 6.3^{\mathrm{e}}$ & $1055 \pm 435^{\mathrm{C}}$ \\
\hline Cortisol (nmol/l) & $367 \pm 35.0$ & $499 \pm 37^{d}$ & $61530 \pm 5424^{c}$ & $267 \pm 49.2$ & $379 \pm 81$ & $42390 \pm 3722^{C}$ \\
\hline Glucose $(\mathrm{mmol} / \mathrm{l})$ & $4.7 \pm 0.07$ & $5.1 \pm 0.09^{d}$ & $863 \pm 18$ & $5.3 \pm 3.4^{f}$ & $5.8 \pm 5.7^{e, f}$ & $891 \pm 38$ \\
\hline Insulin (pmol/l) & $38.7 \pm 7.9$ & $22.2 \pm 5.0^{\mathrm{d}}$ & $6866 \pm 1332$ & $162.9 \pm 49.4^{\mathrm{g}}$ & $74.5 \pm 22.8^{\mathrm{e}, \mathrm{g}}$ & $25589 \pm 8599^{9}$ \\
\hline SS (ng/l) & $12.3 \pm 1.9$ & $27.7 \pm 4.0^{d}$ & $3646 \pm 405$ & $11.9 \pm 2.9$ & $19.7 \pm 3.7^{e}$ & $2659 \pm 640$ \\
\hline PP (pmol/l) & $16.3 \pm 2.0$ & $49.5 \pm 6.6^{d}$ & $4719 \pm 628$ & $26.1 \pm 5.0$ & $92.2 \pm 39.0^{\mathrm{e}}$ & $8028 \pm 2720$ \\
\hline
\end{tabular}

${ }^{\mathrm{a}}$ Mean of two fasting levels, ${ }^{\mathrm{b}} \mathrm{Nadir}$ only for insulin levels, ${ }^{\mathrm{c}} \mathrm{AUC} 120 \mathrm{~min}$.

${ }^{\mathrm{d}} P<0.01$ vs basal and ${ }^{\mathrm{e}} P<0.05$ vs basal (Wilcoxon test), ${ }^{\mathrm{f}} P<0.05$ vs controls and ${ }^{\mathrm{g}} P<0.01$ vs controls (Mann-Whitney test).

\section{Ghrelin injection}

Pituitary hormones and cortisol As shown in Fig. 1, ghrelin elicited a prompt and marked increase of serum GH and PRL levels in both normal subjects and acromegalic patients, without significant differences between the groups as regards peak values and AUC (Table 1). In the acromegalic patients a significant positive correlation was found between IGF-I serum levels and both $\mathrm{GH}$ peak $(r=0.76, P<0.05)$ and net $\mathrm{GH}$ increase $(r=0.78, P<0.05)$. The extent of PRL increase in the two acromegalic patients with hyperprolactinemia (from 31.8 to $91.4 \mu \mathrm{g} / \mathrm{l}$ and from 198 to $552 \mu \mathrm{g} / \mathrm{l}$ respectively), was similar to that observed in those with normal circulating PRL levels (from 14.1 \pm 3.7 to $30.6 \pm 5.5 \mu \mathrm{g} / \mathrm{l})$. Plasma ACTH and serum cortisol levels rose significantly in the controls; their pattern was more variable in the patients with acromegaly, with a significant increase only in ACTH plasma levels (Table 1). Indeed, in three patients, two with a macro- and one with a microadenoma, cortisol responses were blunted or even absent. As far as the patterns of response are concerned (Fig. 1), a statistically significant difference (interaction groups by times) was found only for $\mathrm{GH}(P=0.0146)$ due to the faster and higher peak in acromegalic patients $(P<0.01$ vs controls $)$.

Glucose and GEP hormones In all subjects of both groups plasma glucose levels rose early (mean peak time $29 \pm 4 \mathrm{~min}$ ) and serum insulin levels fell later (mean nadir time $48 \pm 8 \mathrm{~min}$ ) (Table 1 and Fig. 2).
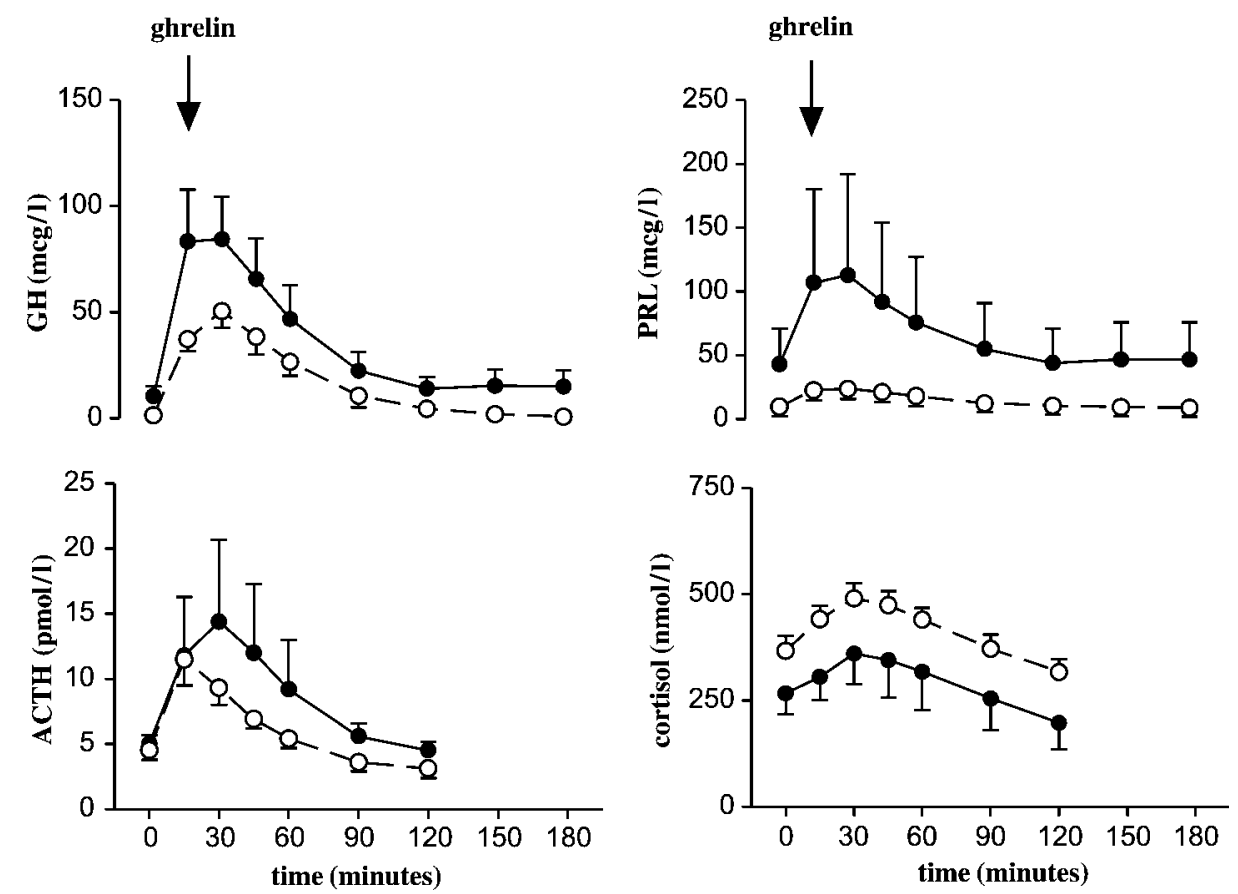

Figure $1 \mathrm{GH}, \mathrm{PRL}, \mathrm{ACTH}$ and cortisol responses to ghrelin administration $(3.3 \mu \mathrm{g} / \mathrm{kg})$ in nine healthy subjects $(O)$ and in seven acromegalic patients (๑). Data are given as means \pm S.E.M. GH: interaction group by time (ANOVA) $P=0.0146$. 

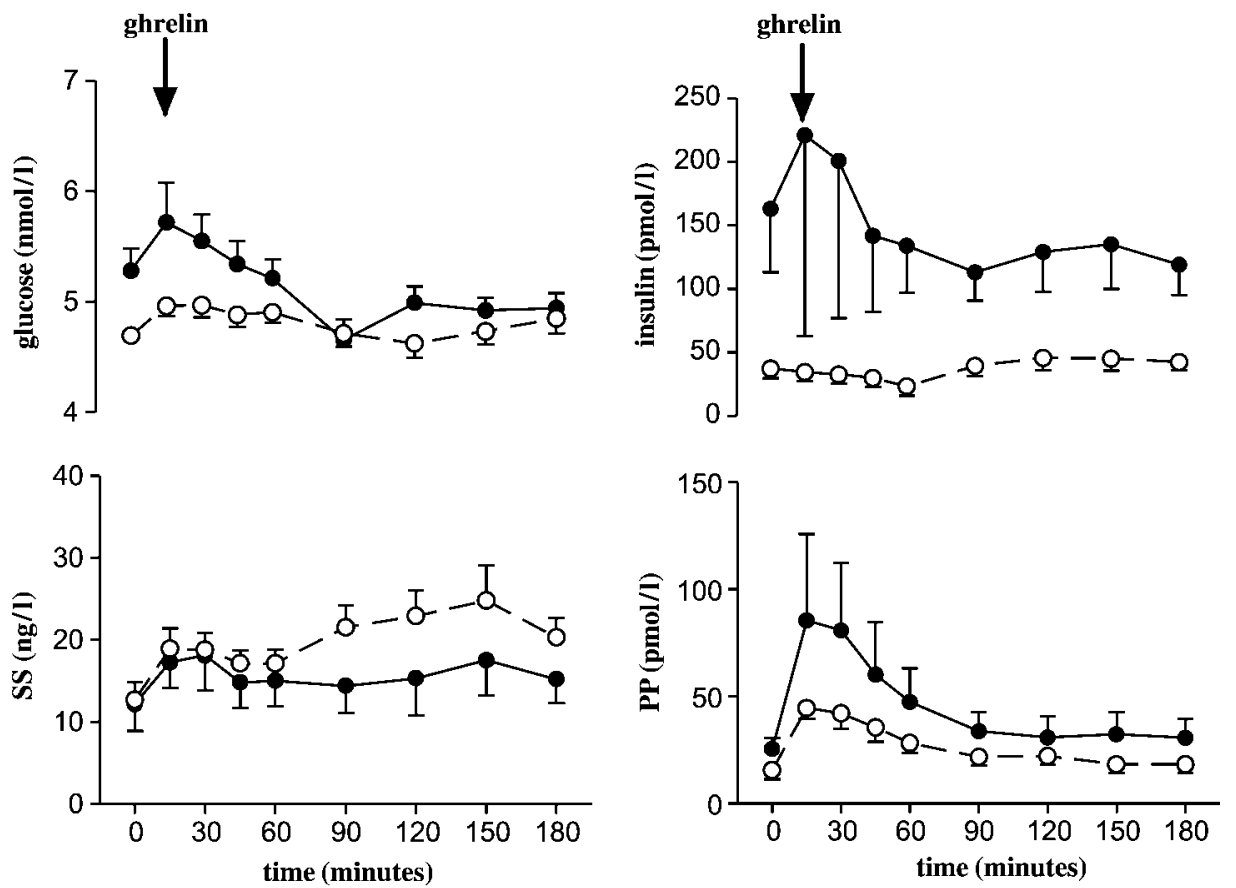

Figure 2 Insulin, glucose, SS and PP responses to ghrelin administration $(3.3 \mu \mathrm{g} / \mathrm{kg})$ in nine healthy subjects $(O)$, and in seven acromegalic patients $(\bullet)$. Data are given as means \pm S.E.M. Glucose: interaction groups by times (ANOVA) $P=0.0086$.

The highest glucose peak $(7.7 \mathrm{mmol} / \mathrm{l}$ at $15 \mathrm{~min})$ occurred in an acromegalic patient, who also showed an increase of insulin levels from 422 to $1167 \mathrm{pmol} / \mathrm{l}$ at $15 \mathrm{~min}$, followed by a progressive decrease, with a nadir of $179 \mathrm{pmol} / \mathrm{l}$ at $90 \mathrm{~min}$. Both glucose peak and insulin nadir values were significantly higher in acromegalic than in healthy subjects (Table 1). Net insulin decrease and $\Delta$ AUC were significantly greater in acromegalic than in healthy subjects $(-80 \pm 21$ vs $-17 \pm 4 \mathrm{pmol} / \mathrm{l}, \quad P<0.005$, and $-4625 \pm 1640$ vs $93 \pm 353 \mathrm{pmol} / \mathrm{l}$ per $3 \mathrm{~h}, \mathrm{P}<0.01)$. A statistically significant different pattern of response occurred in the acromegalic patients only for glucose levels $(P=0.0086$, Fig. 2$)$ due to the higher levels in the early phase $(P<0.01$ vs controls $)$ followed by a sharp decrease until $90 \mathrm{~min}$. All the healthy subjects showed a prompt rise of plasma PP levels, with peak values ranging from 26 to $80 \mathrm{pmol} / \mathrm{l}$ and a biphasic plasma SS response, with a first smaller peak (20.3 $\pm 3.3 \mathrm{pg} / \mathrm{ml}, P<0.005$ vs basal) at $15-30 \mathrm{~min}$ and a second higher peak $(28.0 \pm 4.0 \mathrm{pg} / \mathrm{ml}$, $P<0.005$ vs basal) at $90-150 \mathrm{~min}$. Plasma PP and SS levels rose significantly also in the acromegalic patients. However, the PP response was blunted in two and exaggerated in two others. On the other hand, SS did not show a biphasic pattern, but peak values occurred early in three patients and later in the other four. Mean $\Delta$ AUC was significantly lower in acromegalic than in healthy subjects $(513 \pm 196$ vs $1440 \pm 387 \mathrm{pg} / \mathrm{ml}$ per $3 \mathrm{~h}, P<0.05)$. No statistically different patterns of response was found for both SS and PP between healthy and acromegalic subjects. No significant correlations between changes in SS and insulin levels were observed in the patients with acromegaly, whereas there was a significant correlation between SS $\Delta$ first peak and insulin $\Delta$ nadir levels in the healthy subjects $(r=-0.74, P<0.05)$.

\section{Discussion}

In agreement with previous observations on healthy subjects $(5,10,11)$, the present results demonstrate that the injection of ghrelin, the natural ligand for the GH secretagog (GHS) receptor, stimulates GH, PRL, ACTH, SS and PP secretion, and induces a significant hyperglycaemia that is followed by a decrease in insulin release in both acromegalic and control subjects. This is the first report on the effects of ghrelin in patients with acromegaly and it shows that chronic GH hypersecretion does not markedly influence the hormone responses per se. GHS receptor expression is very high in GH-producing adenomas (16) and hexarelin, a synthetic GHS, possesses GH- and PRL-releasing activity in acromegalic patients $(17,18)$. The positive correlation between the extent of the ghrelin-elicited $\mathrm{GH}$ increase and the basal IGF-I concentrations in acromegalic patients suggests that GHSs are useful tools in assessing GH secretory capacity in both normal and pathological conditions, in agreement with previous findings in healthy subjects after hexarelin administration (19). 
Both ghrelin and hexarelin are able to stimulate ACTH and cortisol release in healthy subjects (6), even if hexarelin is not a useful test of ACTH/cortisol reserve in patients with pituitary diseases (19). Although the ACTH response to ghrelin in acromegalic patients was similar to control subjects, it is noteworthy that the cortisol response did not reach statistical significance. The ACTH/cortisol response to ghrelin, like that of GH, requires functional integrity of the hypothalamus-pituitary unit $(5,20)$, and two of our three patients with impaired cortisol responses had a macroadenoma with extrasellar extension. However, urinary free cortisol was normal in these patients, and no other antero-pituitary deficiencies were present. The interpretation of the lack of cortisol response is probably due to the abnormal cortisol metabolism and accelerated cortisol clearance in acromegalic patients $(21,22)$.

Although GHS receptors have been found also at the GEP level, the mechanisms involved in the variation of plasma glucose and insulin levels induced by pharmacological doses of ghrelin, are still unclear. Indeed, acute hexarelin administration does not influence glucose and insulin levels in healthy subjects (10), but evidence exists that long-term treatment with GHS can impair glucose tolerance in obese subjects (23). In our acromegalic patients, fasting and ghrelin-stimulated plasma glucose levels were higher than those of healthy subjects, but mean $\Delta$ peaks were not different in the two groups. Moreover, insulin levels were higher in acromegalic than in healthy subjects both in fasting conditions and after ghrelin administration, although the net decrease induced by ghrelin was significantly higher in the patients with acromegaly. In both groups of subjects, hyperglycemia could result from either direct hepatic glycogenolytic activity of ghrelin $(24,25)$, or decreased peripheral glucose uptake, or ghrelin-induced release of hyperglycemic hormones such as epinephrine (26) and cortisol. The inhibitory effect of ghrelin on insulin secretion could be mediated by a direct effect on GHS receptors, present on pancreatic islet cells, as suggested by Broglio et al. (10). However, additional mechanisms, including epinephrine release (26), could be activated. Finally, the present findings confirm that in healthy subjects ghrelin induces a biphasic pattern of SS response with a significant negative correlation between the first SS peak and the subsequent insulin nadir, thus suggesting a role for circulating SS in the inhibition of insulin release (11). This mechanism, however, does not fully explain the insulin pattern in patients with acromegaly, as they did not show a significant correlation between SS and insulin changes. On the other hand, in these patients the sharp reduction of glucose levels could favour the inhibition of insulin secretion.

The presence of GHS receptors in the gut and pancreas (5) could well account for the SS- and PP-releasing activity of ghrelin in healthy subjects and in acromegalic patients, although indirect effects mediated by the cholinergic system cannot be excluded (11). Indeed, vagal cholinergic mechanisms have a major role in the control of PP release (27) and also circulating SS levels are partly dependent on vagal tone (28). The observed stimulatory effect of ghrelin on SS and PP secretion suggests the existence of a feed-back loop between ghrelin and SS and ghrelin and PP, as SS has an inhibitory effect on ghrelin secretion (29, 30) and PP has been shown to reduce ghrelin gene expression, at least in rat stomach (31).

In conclusion, the present study demonstrates that ghrelin affects both pituitary and GEP hormones in healthy subjects and in patients with acromegaly in a qualitatively similar way, thus confirming that ghrelin can play a role in linking the endocrine control of energy balance and growth with the regulation of gastrointestinal functions.

\section{Acknowledgements}

The authors thank Rita Deriu for expert nursing assistance, and Dr Ivan Vaghi, Dr Sofia Galofaro, Dr Claudia Terrani and Miss Antonia Maffini for skilled technical assistance. This work was supported in part by research grants from FIRST funds of the University of Milan and from Associazione Amici della Gastroenterologia del Padiglione Granelli (Milan).

\section{References}

1 Kojima M, Hosoda H, Date Y, Nakazato M, Matsuo H \& Kangawa K. Ghrelin is a growth-hormone-releasing acylated peptide from stomach. Nature $1999 \mathbf{4 0 2} 656-660$.

2 Peino R, Baldelli R, Rodriguez-Garcia J, Rodriguez-Segade S, Kojima M, Kangawa K et al. Ghrelin-induced growth hormone secretion in humans. European Journal of Endocrinology 2000 143 R11-R14.

3 Wren AM, Seal LJ, Cohen MA, Brynes AE, Frost GS, Murphy KG et al. Ghrelin enhances appetite and increases food intake in humans. Journal of Clinical Endocrinology and Metabolism 2001 $865992-5997$.

4 Shuto Y, Shibasaki T, Otagiri A, Kuriyama H, Ohata H, Tamura H et al. Hypothalamic growth hormone secretagogue receptor regulates growth hormone secretion, feeding, and adiposity. Journal of Clinical Investigation 2002109 1429-1436.

5 Muccioli G, Tschöp M, Papotti M, Deghenghi R, Heiman M \& Ghigo E. Neuroendocrine and peripheral activities of ghrelin: implications in metabolism and obesity. European Journal of Pharmacology $2002 \mathbf{4 4 0} 235-254$.

6 Ghigo E, Arvat E, Giordano R, Broglio F, Gianotti L, Maccario M et al. Biologic activities of growth hormone secretagogues in humans. Endocrine $20011487-93$.

7 Masuda Y, Tanaka T, Inomata N, Ohnuma N, Tanaka S, Itoh Z et al. Ghrelin stimulates gastric acid secretion and motility in rats. Biochemical and Biophysical Research Communications 2000 276 905-908.

8 Date Y, Nakazato M, Muratami N, Kojima M, Kangawa K \& Matsukura S. Ghrelin acts in the central nervous system to stimulate gastric acid secretion. Biochemical and Biophysical Research Communications $2001280904-907$.

9 Lee H-M, Wang G, Englander EW, Kojima M \& Greeley GH. Ghrelin, a new gastrointestinal endocrine peptide that stimulates 
insulin secretion: enteric distribution, ontogeny, influence of endocrine, and dietary manipulations. Endocrinology 2002143 185-190.

10 Broglio F, Arvat E, Benso A, Gottero C, Muccioli G, Papotti M et al. Ghrelin, a natural secretagogue produced by the stomach, induces hyperglycemia and reduces insulin secretion in humans. Journal of Clinical Endocrinology and Metabolism 2001 86 5083-5086.

11 Arosio M, Ronchi CL, Gebbia C, Cappiello V, Beck-Peccoz P \& Peracchi M. Stimulatory effects of ghrelin on circulating somatostatin and pancreatic polypeptide levels. Journal of Clinical Endocrinology and Metabolism 20038 701-704.

12 Peracchi M, Porretti S, Gebbia C, Pagliari C, Bucciarelli P, Epaminonda $\mathrm{P}$ et al. Increased glucose-dependent insulinotropic polypeptide (GIP) secretion in acromegaly. European Journal of Endocrinology $2001145 \mathrm{R} 1-\mathrm{R} 4$.

13 Arosio M, Porretti S, Epaminonda P, Giavoli C, Gebbia C, Penati C et al. Elevated circulating somatostatin levels in acromegaly. Journal of Endocrinological Investigation 200326 499-502.

14 Cappiello V, Ronchi C, Morpurgo PS, Epaminonda P, Arosio M, Beck-Peccoz $\mathrm{P}$ et al. Circulating ghrelin levels in basal conditions and during glucose tolerance test in acromegalic patients. European Journal of Endocrinology 2002147 189-194.

15 Freda PU, Reyes CM, Conwell IM, Sundeen RE \& Wardlaw SL. Serum ghrelin levels in acromegaly: effects of surgical and longacting octreotide therapy. Journal of Clinical Endocrinology and Metabolism $2003 \mathbf{8 8}$ 2037-2044.

16 Korbonits M, Bustin SA, Kojima M, Jordan S, Adams EF, Lowe DG et al. The expression of the growth hormone secretagogue receptor ligand ghrelin in normal and abnormal human pituitary and other neuroendocrine tumors. Journal of Clinical Endocrinology and Metabolism $200186881-887$.

17 Arosio M, Biella O, Casati G, Guglielmino L, Palmieri E \& Faglia G. Effects of hexarelin (EP23905-MF6003) on circulating GH levels in acromegalic patients. In Frontiers in Endocrinology, vol 9, pp 151-154. Eds M Andreoli \& M Shields. Rome: Ares Serono Symposia Publications, 1994.

18 Ciccarelli E, Grottoli S, Razzore P, Gianotti L, Arvat E, Deghenghi $\mathrm{R}$ et al. Hexarelin, a synthetic growth hormone releasing peptide, stimulates prolactin secretion in acromegalic but not in hyperprolactinaemic patients. Clinical Endocrinology $1996 \mathbf{4 4} 67-71$.

19 Korbonits M, Kaltsas G, Perry LA, Grossman AB, Monson JP, Besser GM et al. Hexarelin as a test of pituitary reserve in patients with pituitary disease. Clinical Endocrinology 199951 369-375.

20 Popovic V, Miljic D, Micic D, Damjanovic S, Arvat E, Ghigo E et al. Ghrelin main action on the regulation of growth hormone release is exerted at hypothalamic level. Journal of Clinical Endocrinology and Metabolism $2003 \mathbf{8 8} 3450-3453$.
21 Trainer PJ, Drake WM, Perry LA, Taylor NF, Besser GM \& Monson JP. Modulation of cortisol metabolism by the growth hormone receptor antagonist pegvisomant in patients with acromegaly. Journal of Clinical Endocrinology and Metabolism $2001862989-2992$.

22 Stewart PM, Toogood AA \& Tomlinson JW. Growth hormone, insulin-like growth factor-I and the cortisol-cortisone shuttle. Hormone Research 200156 (Suppl 1) 1-6.

23 Svensson J, Lonn L, Jansson JO, Murphy G, Wyss D, Krupa D et al. Two-month treatment of obese subjects with the oral growth hormone (GH) secretagogue MK-677 increases GH secretion, fat-free mass, and energy expenditure. Journal of Clinical Endocrinology and Metabolism $1998 \mathbf{8 3} 362$-369.

24 Murata M, Okimura Y, Iida K, Matsumoto M, Sowa H, Kaji H et al. Ghrelin modulates the downstream molecules of insulin signaling in hepatoma cells. Journal of Biological Chemistry $2002 \mathbf{2 7 7}$ 5667-5674.

25 Papotti M, Ghè C, Cassoni P, Catapano F, Deghenghi R, Ghigo E et al. Growth hormone secretagogue binding sites in peripheral human tissues. Journal of Clinical Endocrinology and Metabolism $2000853803-3807$.

26 Nagaya N, Kojima M, Uematsu M, Yamagishi M, Hosoda H, Oya H et al. Hemodinamic and hormonal effects of human ghrelin in healthy volunteers. American Journal of Physiology. Regulatory, Integrative and Comparative Physiology 2001280 R1483-R1487.

27 Schwartz TW. Pancreatic polypeptide: a hormone under vagal control. Gastroenterology $1983 \mathbf{8 5}$ 1411-1425.

28 Chung SA, Greenbeg GR \& Diamant NE. Vagal control of fasting somatostatin levels. Neurogastroenterology and Motility 19957 $73-78$.

29 Nerrelund H, Hansen TK, Ørskov H, Hosodata H, Kojima M, Kangawa K et al. Ghrelin immunoreactivity in human plasma is suppressed by somatostatin. Clinical Endocrinology $2002 \mathbf{5 7}$ 539-546.

30 Barkan AL, Dimiraki EV, Jessup SK, Symons KV, Ermolenko M \& Jaffe CA. Ghrelin secretion in humans is sexually dimorphic, suppressed by somatostatin, and not affected by the ambient growth hormone levels. Journal of Clinical Endocrinology and Metabolism $2003882180-2184$.

31 Asakawa A, Inui A, Yuzuriha H, Ueno N, Katsuura G, Fujimiya M et al. Characterization of the effects of pancreatic polypeptide in the regulation of energy balance. Gastroenterology $2003 \mathbf{1 2 4}$ $1325-1336$.

Received 2 July 2003

Accepted 17 October 2003 